\title{
SARS-CoV-2: recommendations for treatment in intensive care medicine
}

\author{
Markus Köstenberger (D) - Walter Hasibeder · Daniel Dankl · Reinhard Germann · Christoph Hörmann · \\ Michael Joannidis · Klaus Markstaller · Steve-Oliver Müller-Muttonen · Stefan Neuwersch-Sommeregger · \\ Eva Schaden - Thomas Staudinger - Roman Ullrich · Andreas Valentin · Rudolf Likar
}

Received: 20 May 2020 / Accepted: 11 August 2020 / Published online: 18 September 2020

(C) Springer-Verlag GmbH Austria, part of Springer Nature 2020

Summary Coronavirus disease 2019 (COVID-19) progresses mildly in most of the cases; however, about $5 \%$ of the patients develop a severe acute respiratory distress syndrome (ARDS). Of all COVID-19 patients $3 \%$ need intensive care treatment, which becomes a great challenge for anesthesiology and intensive care medicine, medically, hygienically and for technical safety requirements. For these reasons, only experienced medical and nursing staff in the smallest grouping possible should be assigned. For these team members, a consistent use of personal protective equipment (PPE) is essential.

Due to the immense medical challenges, the following treatment guidelines were developed by the ÖGARI (Österreichische Gesellschaft für Anästhesiologie, Reanimation und Intensivmedizin), FASIM (Federation of Austrian Societies of Intensive Care Medicine) and ÖGIAIN (Österreichische Gesellschaft für Internistische und Allgemeine Intensivmedizin und Notfallmedizin).

The recommendations given in this article are to be understood as short snapshots of the moment; all basic guidelines are works in progress and will be regularly updated as evidence levels, new study results and additional experience are gathered.

Keywords SARS-CoV-2 · COVID-19 · ARDS · Personal protective equipment $\cdot$ Respiratory therapy

\section{Introduction}

The recommended procedures for the prognosis, admission, diagnosis and treatment management described in this paper are based on the "ICU Therapy Guidelines for the Treatment of Patients with a SARS

Univ.-Prof. Dr. M. Joannidis

University Hospital Innsbruck, Division of Intensive Care and Emergency Medicine, Department of Internal Medicine, Medical University Innsbruck, Innsbruck, Austria

Univ.-Prof. Dr. K. Markstaller · Assoc. Prof. PD Dr. E. Schaden Department of Anaesthesia, Intensive Care Medicine and Pain Medicine, Medical University of Vienna, Vienna, Austria

\section{Dr. S.-O. Müller-Muttonen}

Department of Anaesthesiology and Critical Care Medicine, Hospital Villach, Villach, Austria

Univ.-Prof. Dr. T. Staudinger · Ao. Univ.-Prof. Dr. R. Ullrich Department of Internal and Critical Care Medicine, Medical University of Vienna, Vienna, Austria

Prim. Univ.-Prof. Dr. A. Valentin, MBA

Department of Internal and Critical Care Medicine, Hospital Schwarzach, Schwarzach, Austria 
CoV 2 Infection", compiled and published by the Austrian Society for Anesthesiology, Reanimation and Intensive Medicine (ÖGARI) and updated in an interdisciplinary paper together with the Federation of Austrian Societies of Intensive Care Medicine (FASIM) and the Austrian Society for Internal and General Intensive Medicine and Emergency Medicine (ÖGIAIN) [1]. Reference is also made to the guidelines of the European Society of Intensive Care Medicine (ESICM) and the Society of Critical Care Medicine (SCCM), "Surviving Sepsis Campaign: Guidelines on the Management of Critically Ill Adults with Coronavirus Disease 2019 (COVID-19)" [2].

The professional societies who have published this information point out specifically that all of their recommendations concern this particular moment of time. Practically every day new publications change the level of information. Such a flood of information can easily lead to insecurity. International and national recommendations for treatment should be considered a work in progress. They are being constantly revised and adapted to the current evidence.

\section{SARS-CoV-2}

The virus SARS-CoV-2 causes the illness coronavirus disease 2019 (COVID-19). The median age of patients testing positive for SARS-CoV-2 is 44.5 years and $60 \%$ are male [3]. The illness in most cases runs a light course (mild pneumonia and slight breathing difficulties) [4]. Only a small proportion of those showing severe symptoms (about 5\% of all COVID-19 patients) are admitted to hospital or treated in the ICUs [5]. In contrast to other infectious illnesses, the severe course of the illness from initial symptoms to life-threatening deterioration is a slow progression.

The transmission is primarily via droplet infection, above all coughing or sneezing but medical procedures, such as suctioning or intubation can transmit SARS-CoV-2. Theoretically, a smear infection via contaminated surfaces or excrement or eye conjunctiva is also possible. The incubation time is 5-6 days (median time 5.7 days), the span is from 1 to 14 days [6] and $97.5 \%$ of all cases become symptomatic after an interval of an average of 11.5 days $[3,7]$.

Patients with COVID-19 treated in ICU have a current mortality rate of $30-70 \%$ according to recent data [8]. This is not an especially high value for older patients with severe acute dyspnea syndrome (ARDS-acute respiratory distress syndrome). Survivors suffer from the usual effects of a long treatment in intensive care. Reports also show that subsequently there are accumulated cases of pulmonary fibrosis. While the evidence for this is weak, the possibilities should be considered in the post-illness monitoring.

\section{Symptoms}

The most common symptoms (Table 1) observed in COVID-19 patients are fever and a usually dry cough [9]. Further possible symptoms are headache and joint pain, additionally colds and sore throats, loss of appetite, weight loss, gastrointestinal syndromes, such as diarrhea, nausea, abdominal pain or vomiting, conjunctivitis, skin rashes, swollen lymph nodes, anosmia, apathy, sensory loss and more rarely respiratory distress [10].

In China, which issues the largest part of empirical data, about $80 \%$ of all known cases have the abovementioned symptoms. About every fifth patient develops severe pneumonia with breathing problems, tachypnea, and/or gas exchange distress in the course of the illness [11]. Patients needing intensive care (about 3\% of the cases) show key symptom dyspnea and $33 \%$ of these show bilateral shading in lung x-rays [12].

\section{Admission}

COVID-19 patients must be isolated immediately upon arrival at the hospital and the health authorities must also be informed.

Table 1 Diagnostic examinations in the intensive care unit (ICU)

\begin{tabular}{|c|}
\hline Initial examination \\
\hline $\begin{array}{l}\text { Swab of the upper respiratory tract: nose and throat swabs; deep respira- } \\
\text { tory tract: sputum, tracheal secretion or mini-BAL sample taking catheter } \\
\text { (CAVE: strict indication positioning for bronchoscopy }+B A L-\text { only for fur- } \\
\text { ther exact diagnosis of a superinfection!) }\end{array}$ \\
\hline Intensive laboratory examinations \\
\hline Blood gas analysis (BGA) \\
\hline 2 blood cultures from 2 different areas \\
\hline $\begin{array}{l}\text { Differential diagnosis: influenza swab, RSV, Legionella or Pneumococcus } \\
\text { Antigens, antigens in urine }\end{array}$ \\
\hline $\begin{array}{l}\text { Thorax x-ray on admission (if need be after inserting a CVC, stomach tube } \\
\text { or after intubation) }\end{array}$ \\
\hline Regular use of sonogram for progression diagnostics (B-lines)! \\
\hline $\begin{array}{l}\text { CT thorax: routine CTs are advised against but recommended for specific } \\
\text { issues }\end{array}$ \\
\hline Further examinations in the course of the illness \\
\hline Laboratory (blood count, albumin, creatinine, urea, bilirubin, LDH, CRP) \\
\hline Laboratory every 3 days, additionally myoglobin, IL-6, CK, CK-MB, troponin \\
\hline Blood gas analysis \\
\hline Sonogram of lungs (pulmonary sonogram?) \\
\hline Echo cardiogram, if needed \\
\hline In case of an increase in PCT (CAVE: superinfection) \\
\hline Blood cultures; urine cultures \\
\hline if needed, sputum, or in intubated patients take tracheal secretions \\
\hline Further examinations for extrathoracic complications \\
\hline $\begin{array}{l}R S V \text { Respiratory syncytial virus, } C V C \text { central venous catheter, } C T \text { com- } \\
\text { puted tomography, } L D H \text { lactatdehydrogenase, CRP C-reactive protein, } \\
\text { IL- } 6 \text { Interleukin } 6, C K \text { Creatine kinase, } C K-M B \text { reatine kinase myocardial } \\
\text { band }\end{array}$ \\
\hline
\end{tabular}


Before entering the room, hospital staff have to put on personal protective equipment (PPE) according to the current standard of hygiene. These include, according to the latest recommendation of the Austrian Agency for Health and Nutritional Security (AGES), the following measures: hand disinfectant, protective gowns, gloves, head covering (surgical cap), protective glasses, masks (FFP2 or FFP3). Additional and continually updated information for hygienic guidelines can be found under: https://www.sozialministerium.at/ Themen/Gesundheit/Antimikrobielle-Resistenzenund-Gesundheitssystem-assoziierte-Infektionen/ Gesundheitssystem-assoziierte-Infektionen/Kranken haushygiene-und-PROHYG/KrankenhaushygienischeInformationen-zu-nCov.html

On leaving the room, the PPE is to be disposed of under consideration of a possible contamination.

There is a basic difference in necessary hygienic measures between normal exposure (for example, visitation in patients' rooms) and activities with aerosol production (e.g. swabbing, intubation, endotracheal suction with open suction systems, disconnecting equipment, tracheotomies, NIPPV [noninvasive positive-pressure ventilation] and HFNC [high flow nasal cannula]). For these activities, the University Clinic for Hospital Hygiene and Infection Control of the Medical University of Vienna defines its own hygiene guidelines: besides a closefitting FFP3 mask (recommended by the European Center for Disease Prevention and Control, ECDC and the Robert Koch Institute, RKI) or a FFP2 mask (WHO [World Health Organization], Federal Health Agency BAG [Bundesamt für Gesundheit]), a longsleeve gown, hood with neck protection, disposable gloves, protective glasses and visor that must be disinfected immediately after use and with expected contamination with fluids, a one-way apron should be worn. A detailed list of hygienic measures can be found under: https://www.meduniwien.ac. at/orgs/fileadmin/krankenhaushygiene/HygMappe/ Richtlinien/101_Novel_Coronavirus_nCoV_vs12.pdf

The common guidelines of ÖGARI, FASIM and ÖGIAIN further recommend that contact with the patients in intensive care be reduced to the absolutely necessary measures for good medical and nursing care, that experienced teams remain small, and the highest measures of self-protection be observed. The same goes for all patient transport.

\section{Diagnostics}

The guidelines define procedures for initial and further examinations in progression. For patients in obligatory intensive care with unclear pneumonia, the usual suspects like influenza, pneumococcus, legionella should be tested for and if possible, tracheal secretion taken for microbiological analysis. In addition, two blood samples from different areas should be taken, if possible at the same time. In case of suspicion of SARS-CoV-2, a nasopharyngeal/ oropharyngeal swab should be submitted for testing. Specimen of lower respiratory tract (e.g. sputum) may have higher sensitivity. If the first finding is questionable and there is a high clinical suspicion with intubated patients, a bronchoalveolar lavage (miniBAL) should be done for extracting secretion from the deep respiratory tract under the highest protective measures for the examiner. A case series also showed that the presence of glassy infiltrates in the thorax CT can also indicate a COVID-19 infection (https://www. drg.de/de-DE/5995/covid-19/) [13].

About $80 \%$ of SARS-CoV-2 positive patients show a lymphopenia in laboratory diagnostics; about $40 \%$ show thrombocytopenia, and increases in LDH and D-dimer cells, and about one third show leukopenia [14]. A massive lymphopenia, high CRP and high LDH values indicate a complicated, severe course of the illness, increased procalcitonin indicates a possible bacterial superinfection.

\section{Treatment of hypoxia}

According to reports, hypoxia is a dominant presentation in the pneumonia caused by SARS-CoV-2. The treatment protocol is based on the treatment guidelines for ARDS [15]. The goal of respiratory therapy is to re-establish an adequate oxygenation $\left(\mathrm{SaO}_{2}\right.$ value $\geq 92 \%$; in patients with COPD $\geq 88 \%$ ) and a clinically relevant improvement of respiratory distress and tachypnea (breathing frequency $<30 / \mathrm{min}$ ). The decision on the method of respiratory support or type of respiration depends among other things on the severity of the illness or the physiological response of the patient to the therapy.

In the case of a diagnosed moderate gas exchange disturbance, a supportive $\mathrm{O}_{2}$ therapy should be initiated if $\mathrm{SaO} 2$ values are $90 \%$ (however should be done with $\mathrm{SaO} 2$ values $\leq 92 \%$, in patients with pre-existing COPD $\leq 88 \%$ ). In cases of acute hypoxia respiratory failure, $\mathrm{SaO} 2$ values should not be increased above $96 \%$.

If the $\mathrm{O} 2$ therapy has insufficient efficacy, a highflow nasal cannula (HFNC) is indicated. The flow should not be set higher than $10-20 \mathrm{~L} / \mathrm{min}$, in order to avoid additional danger for the staff through increased aerosol spread. An additional face mask with reservoir bag should be used for protection against aerosol droplets. If no HFNC is available, a non-invasive intermittent positive pressure ventilation (NIPPV) can alternatively be put over the mask or helmet. If no stabilization is achieved within an hour using HFNC or NIPPV, an early decision for endotracheal intubation should be made, because a delayed intubation is associated with a very poor outcome.

When using noninvasive forms of respiration, the self-protection of the staff is of especially high importance. HME (heat and moisture exchanger) filters 
must be used unconditionally on each mask and other interfaces (as for example respiratory bags).

\section{Intubation and mechanical ventilation}

The success rate of noninvasive forms of respiration in critically ill COVID-19 patients is limited. For patients with severe hypoxia and/or clinically progressive respiratory failure, intubation and mechanical respiration with adequate PEEP values are the only possibilities to stabilize lung function.

Intubation is also a procedure with a very high risk of infection for hospital staff and so must be done under the strictest of personal safety measures and

\section{Table 2 Airway management COVID-19}

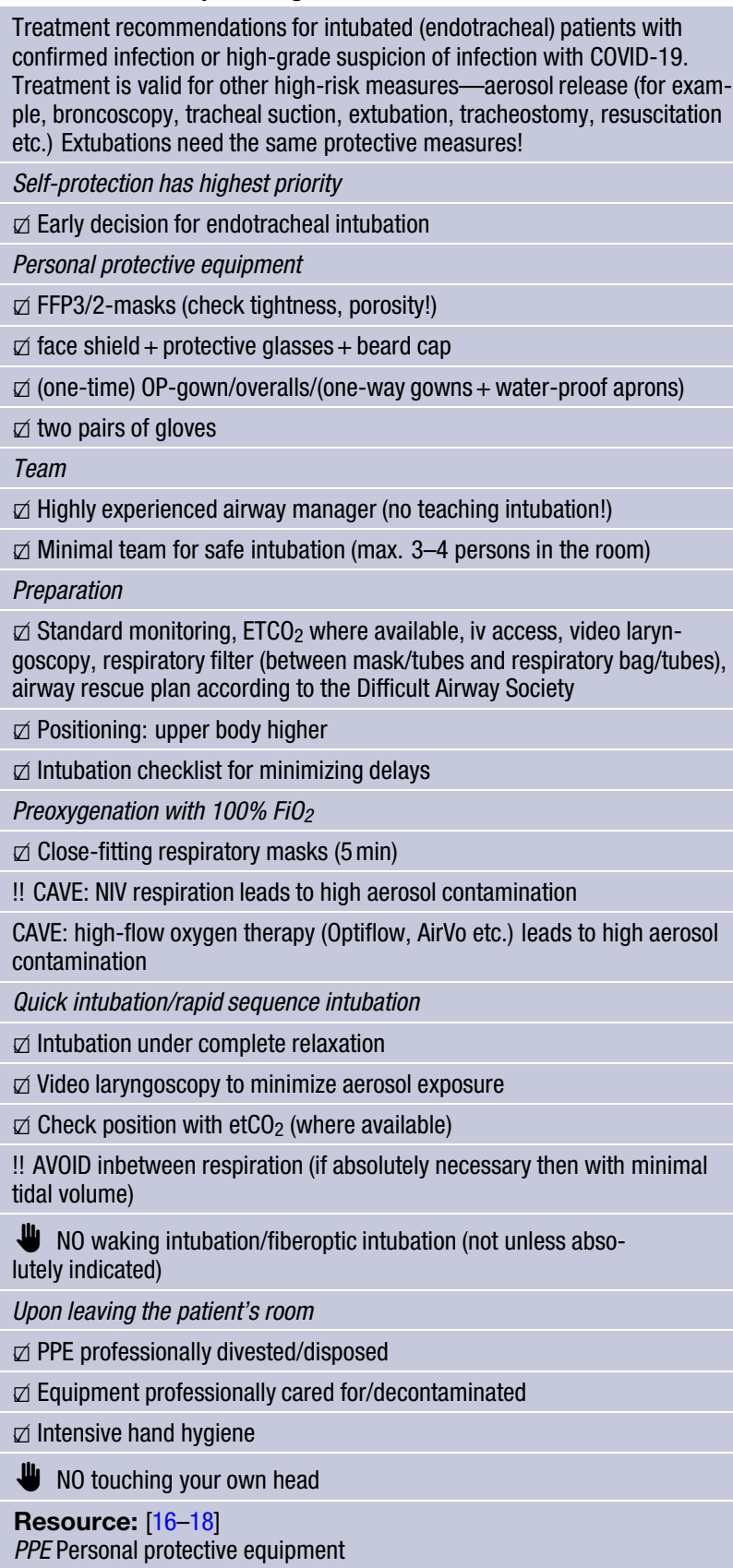

with exact preparation and consultation. The use of a video laryngoscopy is recommended. A compact presentation of the safety measures can be seen in the picture airway management COVID-10 (Table 2).

A closed suction system should always be used with artificial respiration. With every tube disconnection, the tube should be pinched off first with a wide clamp.

The tidal volume is to be limited to $4-6(-8) \mathrm{ml}$ per $\mathrm{kg}$ body weight. Plateau pressure over $30 \mathrm{~cm} \mathrm{H} 2 \mathrm{O}$ is to be avoided. With progression of the lung pathology, especially if atelectasis occurs in independent lung areas, a regular change between supine and prone patient positions and a PEEP adjustment to prevent the formation of new atelectasis is necessary. Measures to minimize transpulmonary pressure should be used methodically, for example measuring esophageal pressure. Early use of the prone position (with Horovitz index $\leq 200$ ) is recommended, whereby the duration of the form of therapy should be about $16 \mathrm{~h}$.

The implementation of a neuromuscular blockade can be considered in individual cases with synchronization problems with respiration. As rescue therapies, inhalation pulmonary vasodilation as well as the use of inhalation $\mathrm{NO}$ can be considered. A moderate hypercapnia (pCO2 $<60 \mathrm{~mm} \mathrm{Hg}$ ) is tolerable with advanced ARDS. Other rescue therapies can be considered, such as a venovenous extracorporeal membrane oxygenation (VV-ECMO). In this case, it is absolutely essential to contact a specialized center.

With the use of transport respirators with one-tube technology, patients must be transported with $100 \%$ oxygen. In case of low $\mathrm{FiO} 2$ concentrations, the machines mix the oxygen with the room air around it, so that virus-contaminated air can get into the machine.

\section{Hemodynamic management}

A restrictive fluid intake therapy is recommended [19]. Noradrenalin should be used as the vasopressor of first choice. With insufficient success, adding vasopressin is recommended. The goal is a mean arterial pressure (MAP) of $60-65 \mathrm{~mm} \mathrm{Hg}$; in the likelihood of hypertension, however, a higher MAP $(75-80 \mathrm{~mm} \mathrm{Hg})$ should be considered.

With unstable patients, additional hemodynamic monitoring, echo cardiogram, invasive hemodynamic monitoring, is recommended. In the case of a clear hemodynamic instability, hydrocortisone can be administered.

There are case reports about myocardial involvement in COVID-19 patients. Severe myocardial problems are still the exception. According to current information, the myocarditis occurring with SARSCoV-2 infections is to be treated like any other viral myocarditis. Even with SARS-CoV-2-induced sepsis, the hemodynamic therapy progresses along the usual algorithms. 


\section{Specific medicinal therapy}

Nutritional therapy, thromboembolic prophylaxis and prevention of stress-related mucosal damage can be prescribed according to criteria of intensive care therapy. On the basis of various case reports, a sufficient thrombosis prophylaxis is especially to be heeded.

Usually procalcitonin stays at a normal level in virus-related illnesses. A sudden PCT increase can indicate an additional bacterial superinfection. Many studies [20] show that too many antibiotics have been prescribed based on the frequency of bacterial superinfections at the start of therapy. If clinical signs or conspicuous laboratory parameters occur (e.g. increasing PCT), antibiotic therapy according an antimicrobial stewardship program is recommended.

At the moment there is no safe specific therapy for SARS-CoV-2. Numerous antiviral and other active substances have been discussed as possible therapy options for severe adult respiratory syndrome (SARS) and Middle East respiratory syndrome (MERS) on the basis of theoretical considerations, case reports and in vitro data [21]. The level of evidence for this is considered, however, extremely low. The current data do not allow treatment recommendations for any substance.

The use of the following antiviral substances therefore can only be recommended after careful riskbenefit consideration and in the framework of studies: remdesivir, favipiravir (Avigan ${ }^{\circledR}$ ), ribavirin or covalescent plasma. Based on the current study situation, the use of other substances like lopinvair/ ritonavir (Kaletra ${ }^{\circledR}$ ) and hydroxychloroquine is not recommended [22-34]. Due to the rapidly changing study situation, it must be pointed out once again that the use of special drugs must be checked extremely carefully.

Tocilizumab (RoActemra ${ }^{\circledR}$ ) or other IL-1 or IL- 6 antagonists could possibly be used within the framework of studies. In this case there is a blockade of IL-6 connecting receptors. CAVE: a viral reactivation, like hepatitis $\mathrm{B}$, is possible.

After such therapy, CRP as well as leucocytes are no longer valid.

Also, no sufficient statement can yet be made about the routine use of corticosteroids. While some studies $[35,36]$ report a positive effect, there are still no benefits found in other studies [37, 38].

The American Heart Association recommends that for patients who have tested positive for the SARSCoV-2 virus and who are being treated for a cardiovascular disease with ACE inhibitors and angiotensin II receptor blockers, these medications should under no circumstances be discontinued. At the moment there is no scientific evidence that ACE inhibitors and angiotensin receptor blockers increase the risk of severe SARS-CoV-2 illnesses [39].

A survey of the interactions of specific therapeutics can be found under www.covid19-druginteractions. org.

\section{Summary}

The COVID-19 illnesses progress mildly in most of the cases; about $5 \%$ of the patients, however, develop a severe acute respiratory distress syndrome (ARDS). Around $3 \%$ of all COVID-19 patients need intensive care treatment, which becomes a great challenge for anesthesiology and intensive care medicine, medically, hygienically and for technical safety requirements. For these reasons, only experienced medical and nursing staff in the smallest grouping possible should be assigned. For these team members, a consistent use of personal protective equipment (PPE) is essential.

For diagnostic purposes, a nasopharyngeal/oropharyngeal swab should be taken with any suspicion of SARS-CoV-2. In cases of a questionable first finding and a high clinical supposition for intubated patients, a bronchoalveolar lavage (miniBAL) should be done for extracting secretion from the deep respiratory tract.

A massive lymphopenia, high CRP and high LDH values indicate a complicated severe progression of the illness. Increased procalcitonin indicates a possible bacterial superinfection.

The success rates of noninvasive forms of respiration are limited. In patients with severe hypoxemia and/or clinically advanced respiratory failure, intubation and mechanical respiration with adequate PEEP values is the only possibility to stabilize pulmonary function. With unstable patients, an additional hemodynamic monitoring should be considered. With massive hemodynamic instability, hydrocortisone can be used. A sufficient thrombosis prophylaxis is to be maintained.

At the moment, there is no safe, specific therapy for SARS-CoV-2. The possible effect of various substances is being studied. The current evidence, however, does not allow for recommendations for use of any of these substances.

The recommendations found in this article are to be understood as short snapshots of the moment; all basic guidelines are works in progress and will be regularly updated as evidence levels, new study results and additional experience are gathered.

Conflict of interest M. Köstenberger, W. Hasibeder, D. Dankl, R. Germann, C. Hörmann, M. Joannidis, K. Markstaller, S.-O. Müller-Muttonen, S. Neuwersch-Sommeregger, E. Schaden, T. Staudinger, R. Ullrich, A. Valentin, and R. Likar declare that they have no competing interests.

\section{References}

1. Köstenberger M, Hasibeder W, et al. ICU Therapy guideline for the treatment of patients with a SARS CoV2 infection. 2020. https://www.anaesthesie.news/wpcontent/uploads/\%C3\%96GARI-FASIM-\%C3\%96GIAINGuideline-NEU-Covid19-290320.pdf. Accessed 30 Mar 2020. 
2. Alhazzani D, Hylander Moller M, Arabi YM, et al. Surviving sepsis campaign: guidelines on the management of critically ill adults with Coronavirus disease 2019 (COVID-19). IntensiveCare Med. 2020; https:// doi.org/10.1007/s00134020-06022-5.

3. Lauer Stephen A, Grantz Kyra H, Bi Qifang, Jones Forrest K, Zheng Qulu, Meredith Hannah R, Azman Andrew S, Reich Nicholas G, Lessler Justin. The Incubation Period of Coronavirus Disease 2019 (COVID-19) From Publicly Reported Confirmed Cases: Estimation and Application. Ann Intern Med. 2020;172(9):577-582. https://doi.org/10.7326/M200504.

4. NHC. Diagnosis and treatment protocol for novel Coronavirus pneumonia. 2020. http://www.kankyokansen.org/ uploads/uploads/files/jsipc/protocol_V7.pdf. Accessed 26Mar 2020.

5. Murthy S, Gomersall CD, Fowler RA. Care for critically ill patients with COVID-19. JAMA. 2020; https://doi.org/10. 1001/jama.2020.3633.

6. Robert Koch Institut. SARS-CoV-2 Steckbrief zur Coronavirus-Krankheit-2019.. https://www.rki.de/DE/Content/ InfAZ/N/Neuartiges_Coronavirus/Steckbrief.html. Accessed 26 Mar 2020.

7. Bi Q, Wu Y, Mei S, et al. Epidemiology and transmission of COVID-19 in Shenzhen China: analysis of 391 cases and 1,286 of their close contacts. medRxiv. 2020; https://doi. org/10.1101/2020.03.03.20028423.

8. WHO. Situation report.. https://www.who.int/emergencies/ diseases/novel-coronavirus-2019. Accessed26 Mar 2020.

9. Guan W, Zheng-yi H, Yu H, et al. Clinical characteristics of Coronavirus disease 2019 in China. N Engl J Med. 2020; https://doi.org/10.1056/NEJMoa2002032.

10. Wang D, Hu B, Hu C, et al. Clinical characteristics of 138 hospitalized patients with 2019 novel Coronavirus-infected pneumonia in Wuhan, China. JAMA. 2020;323(11):1061-9. https://doi.org/10.1001/jama.2020.1585.

11. Wu Z, Mc Googan JM. Characteristics of and important lessons from the Coronavirus disease 2019 (COVID-19) outbreak in China. JAMA. 2020; https://doi.org/10.1001/ jama.2020.2648.

12. Deutsche Röntgengesellschaft. COVID-19. 2020. https:// www.drg.de/de-DE/5995/covid-19/. Accessed 8 May2020.

13. Shi H, Han X, Jiang N, et al. Radiological findings from 81 patients with COVID-19 pneumonia in Wuhan, China: a descriptive study. Lancet Infect Dis. 2020;2(0):30086-30084. https://doi.org/10.1016/S1473-3099.

14. Sharma R, Agarwal M, Gupta M, Somendra S, Saxena SK. Clinical characteristics and differential clinical diagnosis of novel Coronavirus disease 2019 (COVID-19). In: Saxena S, editor. Coronavirus disease 2019 (COVID-19). Medical virology: from pathogenesis to disease control. Singapore: Springer; 2020.

15. Papazian L, et al. Formal guidelines: management of acute respiratory distress syndrome. Ann Intensive Care. 2019;9:69. https://doi.org/10.1186/s13613-019-0540-9.

16. World Federation of Societies of Anaesthesiologists. Coronavirus-guidance for anaesthesia and perioperative providers. https://www.wfsahq.org/latest-news/ latestnews/943-coronavirus-staying-safe

17. Peng Philip WH, et al. Outbreak of a new coronavirus: what anaesthetists should know. British Journal of Anaesthesia. 2020;124(5):497-501.

18. Schebesta K, Rössler B. Hygienerichtlinie Coronavirus SARS-CoV2 (COVID-19), Krankenhaushygiene MedUni Wien. Interdisziplinäres Airwaymanagement Team MedUniWien, Version 1.1., 17.03.2020.
19. Joannidis M, Forni LG, Klein SJ, et al. Lung-kidney interactions in critically ill patients: consensus report of the Acute Disease Quality Initiative (ADQI) 21 Workgroup. intensive Care Med. 2020;46(4):654-72. https://doi.org/10.1007/ s00134-019-05869-7.

20. Rawson TM, Moore L, Zhu N, et al. Bacterial and fungal coinfection in individuals with coronavirus: a rapid review to support COVID-19 antimicrobial prescribing. Clin Infect Dis. 2020; https://doi.org/10.1093/cid/ciaa530.

21. Zhang L, Liu Y. Potential interventions for novel coronavirus in China: a systematic review. J Med Virol. 2020;92:479-90. https://doi.org/10.1002/jmv.25707.

22. Agostini ML, Andres EL, Sims AC, et al. Coronavirus susceptibility to the antiviral remdesivir (GS-5734) is mediated by the viral polymerase and the proofreading exoribonuclease. mBio. 2018; https://doi.org/10.1128/mBio.00221-18.

23. Brown AJ, Won JJ, GrahamRL, etal. Broad spectrum antiviral remdesivir inhibits human endemic and zoonotic deltacoronaviruses with a highly divergent RNA dependent RNA polymerase. Antiviral Res. 2019;169:104541.

24. DeWit E, Feldmann F, Cronin J, et al. Prophylactic and therapeutic remdesivir (GS-5734) treatment in the rhesus macaque model of MERS-CoV infection. Proc Natl Acad Sci. 2020;117(12):6771-6. https://doi.org/10.1073/pnas. 1922083117.

25. Gordon CJ, Tchesnokov EP, Feng JY, et al. The antiviral compound remdesivir potently inhibits RNA-dependent RNA polymerase from Middle East respiratory syndrome coronavirus. J Biol Chem. 2020; https://doi.org/10.1074/ jbc.AC120.013056.

26. Ko WC, Rolain JM, Lee NY, et al. Arguments in favour of remdesivir for treating SARS-CoV-2 infections. Int JAntimicrob Agents. 2020; https://doi.org/10.1016/j.ijantimicag. 2020.105933.

27. Cortegiani A, Ingoglia G, Ippolito M, et al. A systematic review on the efficacy and safety of chloroquine for the treatment of COVID-19. J Crit Care. 2020; https://doi.org/ 10.1016/j.jcrc.2020.03.005.

28. Sheahan TP, Sims AC, Graham RL, et al. Broad-spectrum antiviral GS-5734 inhibits both epidemic and zoonotic coronaviruses. Sci Transl Med. 2017;9(396):eaal3653. https://doi.org/10.1126/scitranslmed.aal3653.

29. Sheahan TP, Sims AC, Leist SR, et al. Comparative therapeutic efficacy of remdesivir and combination lopinavir, ritonavir, and interferon beta against MERS-CoV. Nat Commun. 2020; https:// doi.org/10.1038/s41467-019-13940-6.

30. Vincent MJ, Bergeron E, Benjannet S, et al. Chloroquine is apotentinhibitor ofSARS coronavirusinfection and spread. Virol J.2005;2:69.

31. Wang M, Cao R, Zhang L, et al. Remdesivir and chloroquine effectively inhibit the recently emerged novel coronavirus (2019-nCoV) in vitro. Cell Res. 2020; https://doi.org/10. 1038/s41422-020-0282-0.

32. KeyaertsE, Vijgen L, Maes P, etal. In vitro inhibition of severe acute respiratory syndrome coronavirus by chloroquine. Biochem Biophys Res Commun. 2004;323:264-8.

33. Jean SS, Lee PI, Hsueh PR. Treatment options for COVID19: the reality and challenges. J Microbiol Immunol Infect. 2020;53(3):436-43. https://doi.org/10.1016/j.jmii.2020.03. 034.

34. Harapan H, Itoh N, Yufika A, et al. Coronavirus disease 2019 (COVID-19): a literature review. J Infect Public Health. 2020;13(5):667-73. https://doi.org/10.1016/j.jiph.2020.03. 019.

35. Horby P, Shen Lim W, Emberson J, et al. Effect of dexamethasone in hospitalized patients with COVID-19: preliminary 
report. RECOVERY Collaborative Group. medRxiv. 2020; https://doi.org/10.1101/2020.06.22.20137273.

36. Johnson RM, Vinetz JM. Dexamethasone in the management of covid-19. BMJ.2020;370:m2648.

37. Yang JW, Yang L, Luo RG, Xu JF. Corticosteroid administration for viral pneumonia: COVID-19 and beyond. Clin MicrobiolInfect. 2020; https://doi.org/10.1016/j.cmi.2020. 06.020 .

38. Zha L, Li S, Pan L, et al. Corticosteroid treatment of patients with coronavirus disease 2019 (COVID-19). Med J Aust. 2020;212(9):416-20. https://doi.org/10.5694/mja2.50577.
39. Reynolds HR, Adhikari S, Pulgarin C, et al. Renin-angiotensin-aldosterone system inhibitors and risk of Covid19. N Engl J Med. 2020; https://doi.org/10.1056/ NEJMoa2008975.

Publisher's Note Springer Nature remains neutral with regard to jurisdictional claims in published maps and institutional affiliations. 